\title{
Scientific aspects of the survey and evaluation of the technical state in implementation of preservation projects of cultural heritage objects
}

\author{
Vera Akristiniy ${ }^{1, *}$ \\ ${ }^{1}$ Moscow State University of Civil Engineering, Yaroslavskoeshosse, 26, Moscow, 129337, Russia
}

\begin{abstract}
The article examines the basic provisions that regulate the composition and volume of complex engineering and technical studies needed for the definition of a technical condition, implementation of repair and restoration projects, conservation and adaptation for the modern use of cultural heritage objects, as well as to obtain reliable data on occurrence of the causes of deterioration and developing recommendations to ensure their preservation.
\end{abstract}

\section{Introduction}

Complex scientific and engineering studies of technical condition of cultural heritage objects include the following types of engineering studies: survey of bases and foundations; survey and calculation of load-bearing and enclosing structures; survey of the state of construction materials; determination of temperature and humidity conditions and ecological state structures and buildings [2]; monitoring of the technical condition of structures and temperature and humidity object regime during the operation period, conduct research, design, production (restoration, conservation works, adaptation) of the object [1].

A survey of cultural heritage objects should be carried out mainly by non-destructive methods. All opening, probing and other impacts on the design of objects should be carried out in strict accordance with the research program.

In order to ensure preservation of immovable monuments of history and culture is necessary to organize the monitoring of their technical condition. When performing restoration, repair and other works, monitoring should be organized before the start of work. The time period monitoring of the operation was to determine the trends and the intensity of the processes extension taking place with the object of cultural heritage [14].

The structure of the monitoring and intensity of the surveys should be determined depending on the purpose of the monitoring organization and the state of an object defined by the technical conclusion or the object observations results which implemented by the operating organizations [16].

${ }^{*}$ Corresponding author: 7824666@mail.ru 


\section{The methods used to study the technical condition of the objects of cultural heritage}

Complex of engineering and technical researches of the object of cultural heritage includes [3]:

- survey of elements or the entire foundations complex with the definition of their condition and load bearing capacity;

- a survey of bearing and enclosing structures, including the determination of its constructive execution, characteristics of materials and load bearing capacity;

- measuring work;

- materials science research, including the determination of physical, physico-chemical, of physico-mechanical characteristics of materials and damage caused by various factors;

- study of temperature and humidity regime of the object;

- engineering and environmental survey [4];

- monitoring of various parameters of the object at the time of research, design and restoration works.

Engineering survey phases are linked to sections of the scientific and project documentation as follows [7]:

- preparation for conducting a preliminary examination and (visual) inspection is performed during the process of the preliminary work;

- detailed inspection is conducted in the process of comprehensive scientific research.

At various stages of the research of cultural heritage objects, as a rule, are being developed the following types of research documents, which represent the state of the object [13]:

- at the stage of "preparation for conducting a preliminary examination and (visual) inspection" are conducted preparatory activities and inspection, allowing to compile: Certificate of the technical condition of the cultural heritage object and the report on the preliminary engineering survey;

- atthestageof " detailed inspection ", conduct research which allows compile A technical report on the results of the engineering surveys, including reports on all parts of the study (diagnosis of the state of materials, the study of temperature and humidity environment, environmental conditions, etc.).;

- at the stage of production of repair and restoration work - a report on the additional engineering inspection of structures and materials;

- after production of the repair and restoration work on the object:

- the research and restoration report on the restoration work being conducted [8].

- reports on the results of monitoring of various parameters (stress-strain state, the temperature and humidity conditions, and others.), including forecasts of the development of processes and the recommendation of methods to eliminate their negative impact on the manufacturing process fulfilled during repair and restoration work and maintenance of cultural heritage objects [16].

The volume and composition of the work performed during the technical and engineering inspection, should be determined by the Program, formed in each case, depending on the goals and objectives, as well as the state and level of difficulty of each individual object at obligatory observance of existing standards to ensure the accuracy of the information received [14].

Stagesofthesurvey [13]: 
a. Preliminary work (preliminary studies presuppose the object inspection, its elements, and etc., The development of the composition of the planned works, performing the prior (visual) object survey, preparation of a report of the technical state of cultural heritage objects. Formulated or specified the aim and is determined or specified the object monitoring structure. Refinements conducted in the presence of previously organized monitoring.

b. Detailed engineering and technical studies [9].

Detailed survey of constructions includes:

- execution of instrumental measurements of individual structures, their elements, junctions and components of structural parts, including the pits and probing;

- detection of previously repaired places, reconstructions, additional structures, strengthening, or replacement of constructions;

- the instrumental definition of defects and damage parameters (width fracture opening, displacements, flexures, etc.);

- graphic and / or photographic images of the locations and nature of defects and damage (in the case of performing photo fixation necessarily drawn a scheme indicating points and photographing direction) [10];

- conducting field structural testing (if necessary);

- determining the actual strength and deformation characteristics of the materials from which made the main building constructions and their elements;

- determining the actual operating loads and impacts that perceived by the constructions at the time of the survey, as appropriate, taking into account the possible influence of the soil strain base;

- determining the actual design scheme of the building or structure and its individual construction elements;

- definition of calculating forces in constructions, that perceive current loads, and, in the case of building adaptation, additional projected operating loads;

- calculation of the bearing capacity of constructions and parts of the building taking into account the results of the survey;

- cameral processing and analysis of the survey results and calibration calculations;

- determining the causes of defects and damages in constructions;

- compose technical conclusion with findings about the technical condition of constructions on the results of the survey;

- diagnostics of the construction materials condition;

- the results of engineering and environmental studies.

c. Measuring work at the engineering and technical researches [6].

Measurements of constructions of cultural heritage objects, depending on the required degree of detail of necessary graphic materials are divided into the following types:

- schematic;

- architectural;

- architectural and archaeological.

Architectural measurements of constructions are performed in order to obtain graphic materials for engineering and technical calculations, producing original graphics bases for conducting of project works. Results of architectural measurements generally consist of drawings of floor plans, sections, facades, interiors, three-dimensional schemes and models, drawings of individual structures of the object. In the drawings, made according to architectural measurements are plotted [15]:

1. actual contours of constructions of object with regard to their geometric shape and position;

2. dimensions and height marks of constructions; 
3. coaxiality measurement results of support structures, deflection size, bending, deviations from the vertical, buckling, bias, displacements, shifts, etc.

Architectural and archaeological measurements of constructions include volumes of architectural constructions measurements, in addition to which must be presented[11]:

4. location of places of cracks, fractures and the size of their disclosure (in stone and reinforced concrete structures);

5. location of places and magnitude of corrosion damage; the straightness measurements of the compressed elements, distortion, sagging, state of elements with abrupt changes in cross-sections, the actual length; the attachment methods the abutting elements; placement, quantity and diameter of the screws or rivets (in metallic structures);

6. location of places and magnitude: distortion and warping of elements, joints disorder and breaks in the cross-sections of elements or cracks along their length; areas of biological destruction of timber (wooden structures);

7. availability, location, magnitude and class of reinforcement; signs and the intensity of corrosion of reinforcement and embedded parts, as well as the condition of protective layers (in reinforced concrete structures).

d. A constructions survey of cultural heritage object [14].

e. Checking calculation of constructions (the calculation may be local to determine the load bearing capacity of the individual components or to assess the overall stress-strain state of the structures of the object as a whole).

f. Diagnosis of biological damage to construction materials (microbiological, mycological, algological, lichenological and aero-micro-biological studies usually performed in conjunction with the study of humidity regime of constructions, and the air environment) [12].

g. Diagnosis of structural-phase state of materials, the main objective of which is to determine the type of the material damage in consequence of physical and chemical processes and the acquisition of a complex qualitative and quantitative characteristics, reflecting the nature of the destructive processes occurring in the material, in the necessary volume to diagnose the condition, determine the cause of damage and the development of the project of restoration of cultural heritage object [12].

h. The study of temperature and humidity state of the object. The temperature-humidity regime of cultural heritage objects is a dynamic value, which is characterized by two components: changes in microclimate of internal premises and the cycle change of humidity and temperature regimes of construction materials (including murals). Microclimate is influenced by the climate change of outside air, humidity state of the structures and systems of heating, ventilation and air conditioning. Study and control of air regime of the object are required for the evaluation and optimization of the conditions of preservation of the interior, as well as for the conditions of preservation of constructions and monumental painting [14].

i. Monitoring the technical state of the monuments, which includes a complex observation system designed to ensure their preservation [18].

j. Survey of technical state of constructions during the production of repair and restoration work. The need for engineering studies of cultural heritage objects at the time of repair and restoration work caused due to the unavailability of some constructions for direct access and limited space and forced limited places of opening of constructions and during the main survey [15].

After the analysis of the peculiarities of the cultural heritage of the developed conceptual model for complex monitoring of the technical state of objects (figure 1) [19].This model reflects the full range of activities necessary for a comprehensive assessment of the state of the object. Survey on the proposed methodology provides seven types of monitoring of the technical state of the object: archaeological monitoring, 
historical landscape monitoring, monitoring for the conservation of urban space, ecological monitoring, geological monitoring, monitoring cultural heritage, analytical monitoring. Implementation of each type of monitoring determined by the characteristics of a particular object [17].

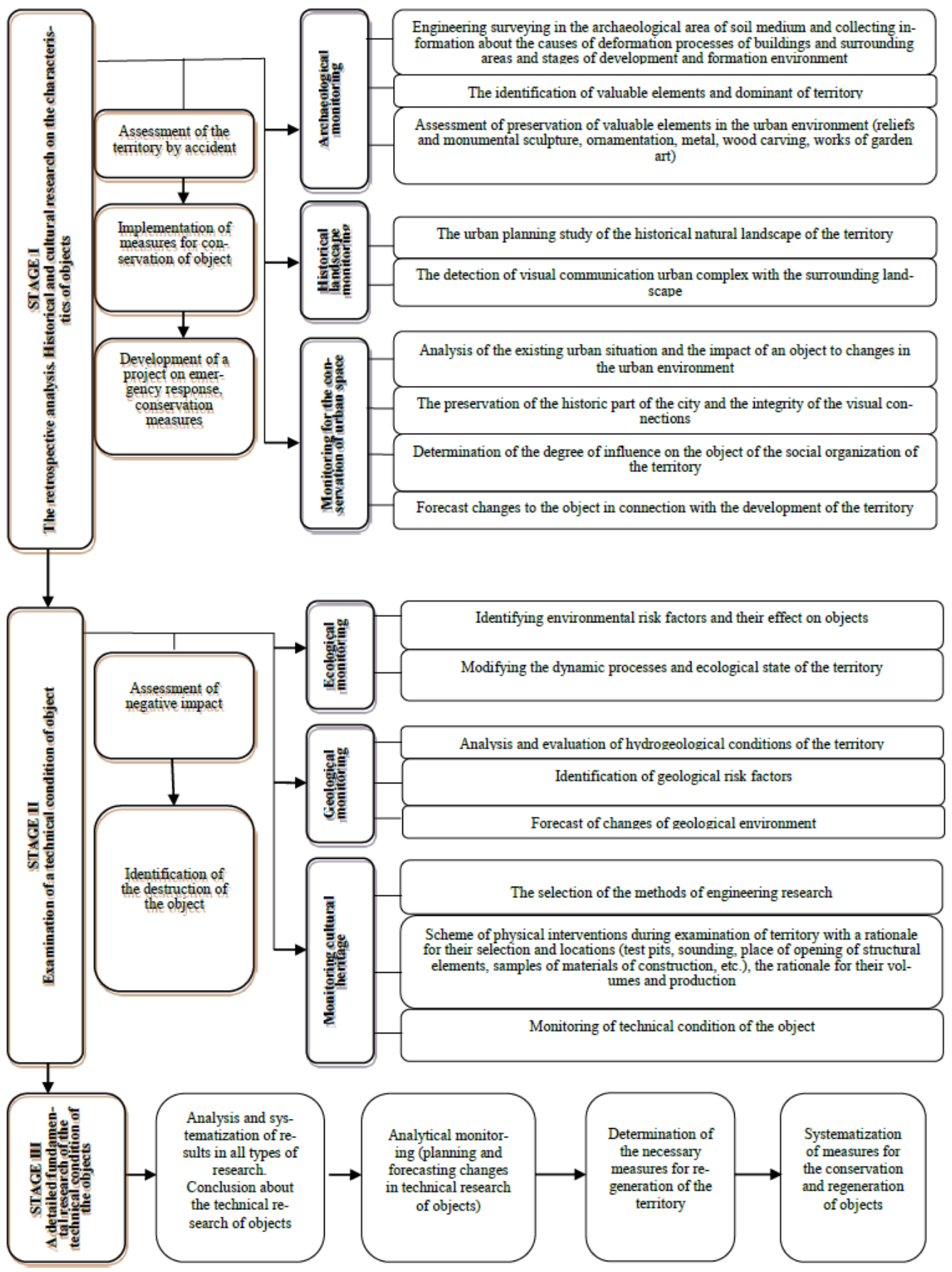

Fig. 1. Conceptual model for complex monitoring of the technical condition of objects. 


\section{Practical results}

The most effective method of survey and monitoring the technical condition of the object of cultural heritage is implemented in the restoration project of Kremlin Ensemble and "Menovyy Dvor" in Tobolsk (Figure 2), which implements by following executives [5]:

- Committee on protection and use of historical and cultural heritage of the Tyumen region;

- Ltd. ISV "SibSpetsStroyRestavratsiya";

- Ltd."EvroStroyRestavratsiya".

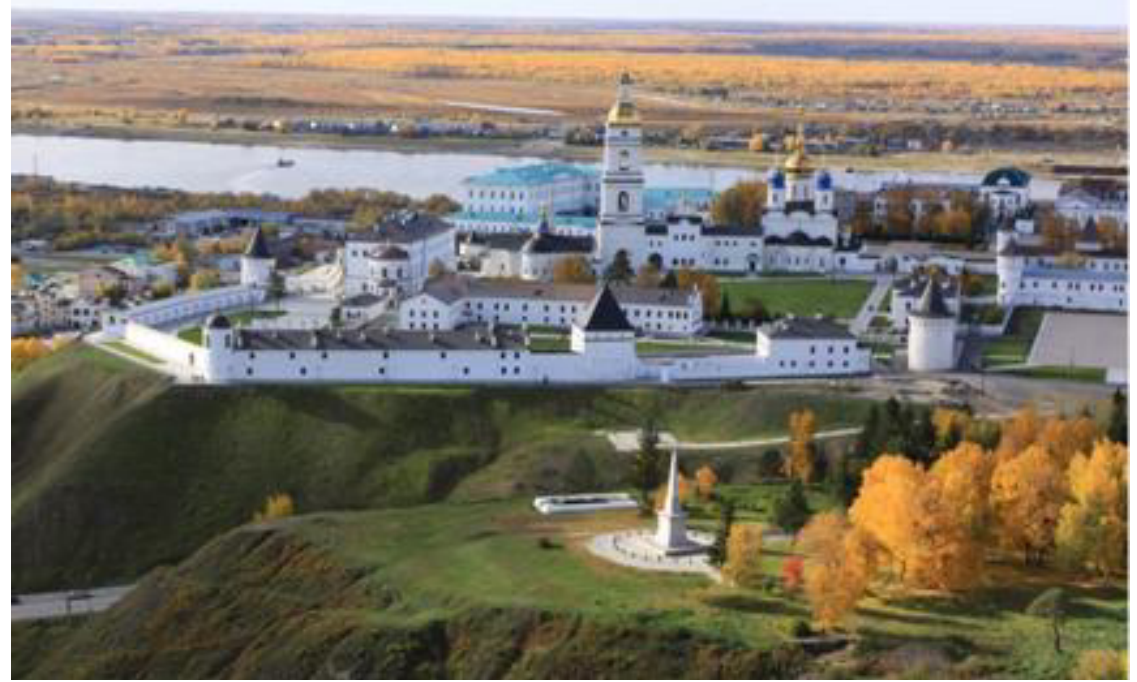

Fig.2. Current state of the Kremlin and Menovyy Dvor.

The general condition of buildings and structures of the Kremlin ensemble and Menovyy Dvor before restoration can be described as satisfactory. After the technical inspection was conducted by the following conclusion: in many buildings and facilities the original layout has been changed; Many basements have not been used or have been filled up by soil, immured entrances; brickwork of walls and foundations were in a wet state, there was the destruction of the exterior brickwork of makeup and the destruction of the finishing layer; wooden roof structures in many places were struck by rot, roofing iron rusted, missing gully; interior decoration has been partially lost or is closed by suspended ceilings and plasterboard; windows was being dried up and was cracked, the majority of the door panels has been replaced with a replica; lost many elements of architectural design (both internal and external).Walls of Pryamskoyvzvoz and slopes of Cape Troitskiy needs to be strengthened (Figure 3). It was also necessary to complete landscaping with restoration of small architectural forms [5]. 


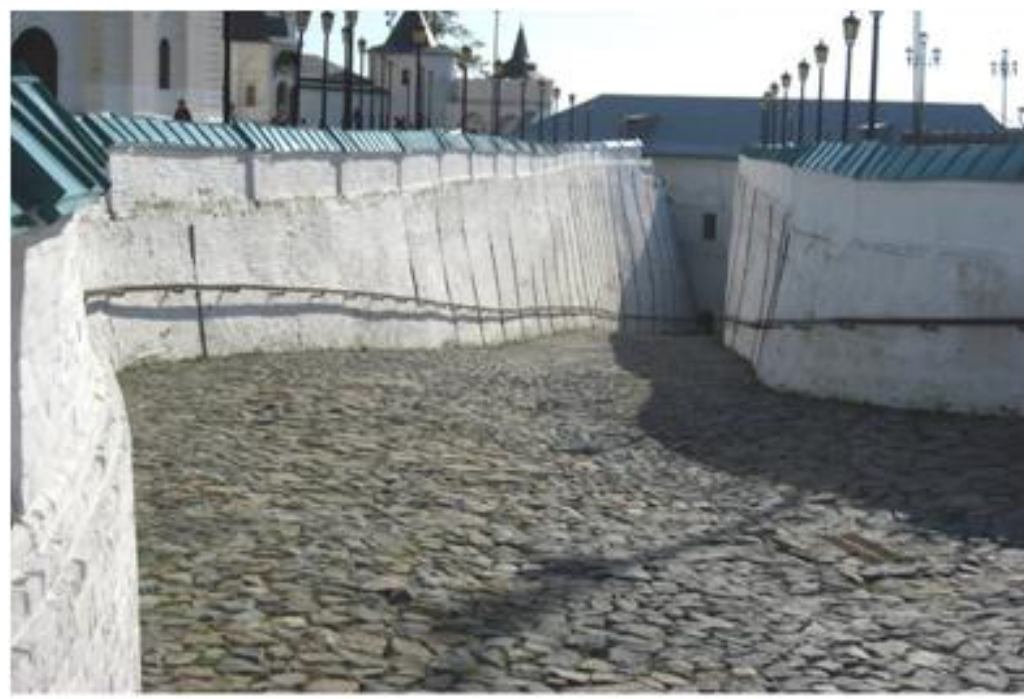

Fig. 3.Pryamskoyvzvoz.

The main problem faced by the restorers, - the scale of the ensemble, the multiplicity of its individual components, as well as a large diversity of work that had to be done to complexly restore the monument (Figure 4).

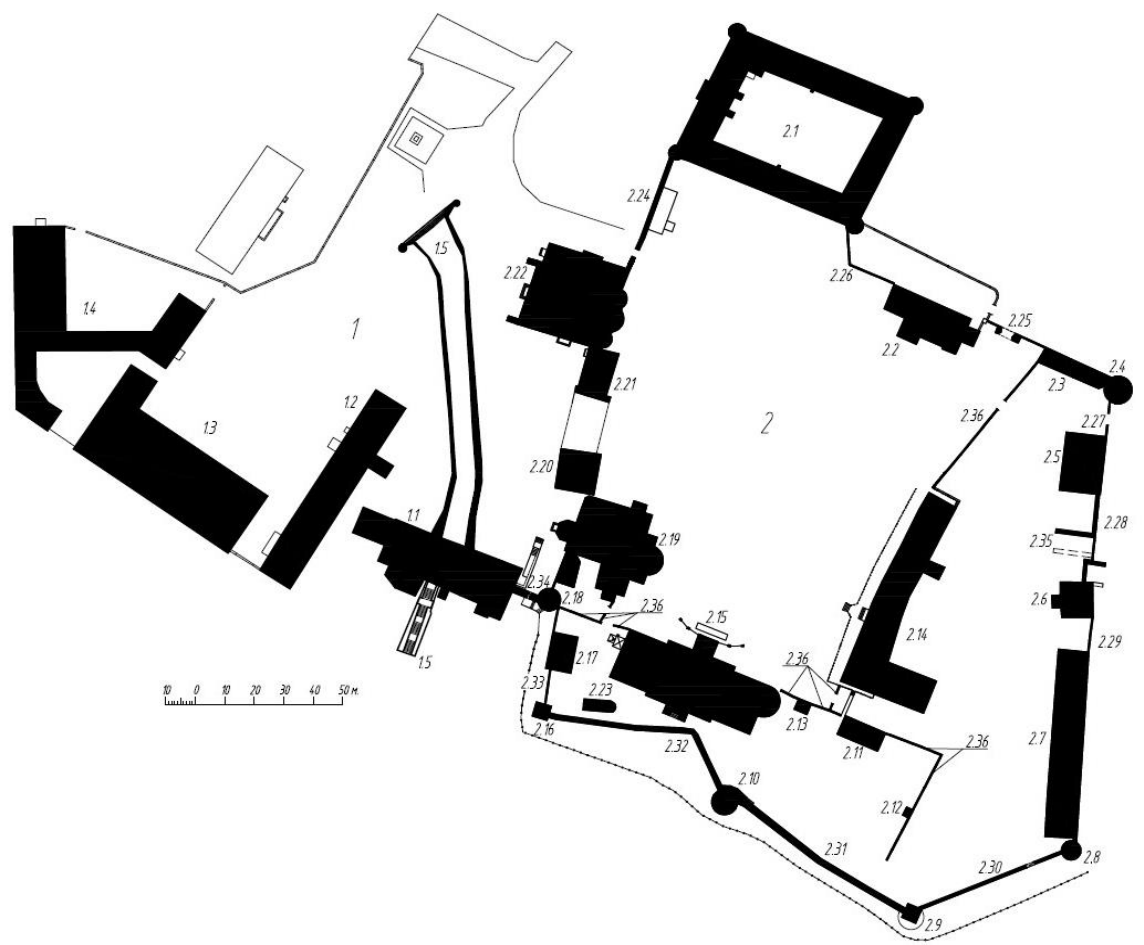

Fig.4. Layout of the Ensemble of the Kremlin and Menovyy Dvor, where 1- Small (Voznesensky) city, 2-Sofiyskiy arkhiyereyskiy courtyard, 3- Gostinyy (Menovoy) courtyard.

The whole complex of survey, design, repair and restoration works in the Kremlin Ensemble objects and exchange yard was divided into main areas: 
1. Emergency measures.

2. Preliminary research and design and making of design and estimate documentation.

3. Engineering preparation and strengthening of structures and foundation soils.

4. Repair and restoration work.

5. Engineering support of buildings and structures.

6. Adaptation of buildings and structures.

7. Complex improvement of internal and surrounding areas close to city. The main types of repair work on sites become:

- slope reinforcement of Tobolsk Kremlin (Picture 4);

- strengthening the foundations of soil base by injecting cement mortar into the subsoil by the method of cuff technology;

- restoration of the blind area and its thermal insulation;

- setting up of horizontal and vertical injectable waterproofing;

- restoration and strengthening of brickwork foundations;

- restoration of damaged areas of stone walls by masonry renovation method and restoration of the destroyed brick decorative by daub;

- restoration of historic space-planning decisions of buildings, disclosing and restoration of window and door openings;

- restoration or reconstruction of the existing analogs for doors and windows, decor elements;

- decoration of facades and interiors matching the historical period of construction monuments, according to project;

- engineering and communication support buildings and structures;

- providing accessibility for people with limited mobility;

- implementation of a balanced functional load on the monuments, according to the design solutions, making it possible to fit into existing buildings without violating the "object of protection" and completing the application of technical specifications for the adaptation;

- landscaping.

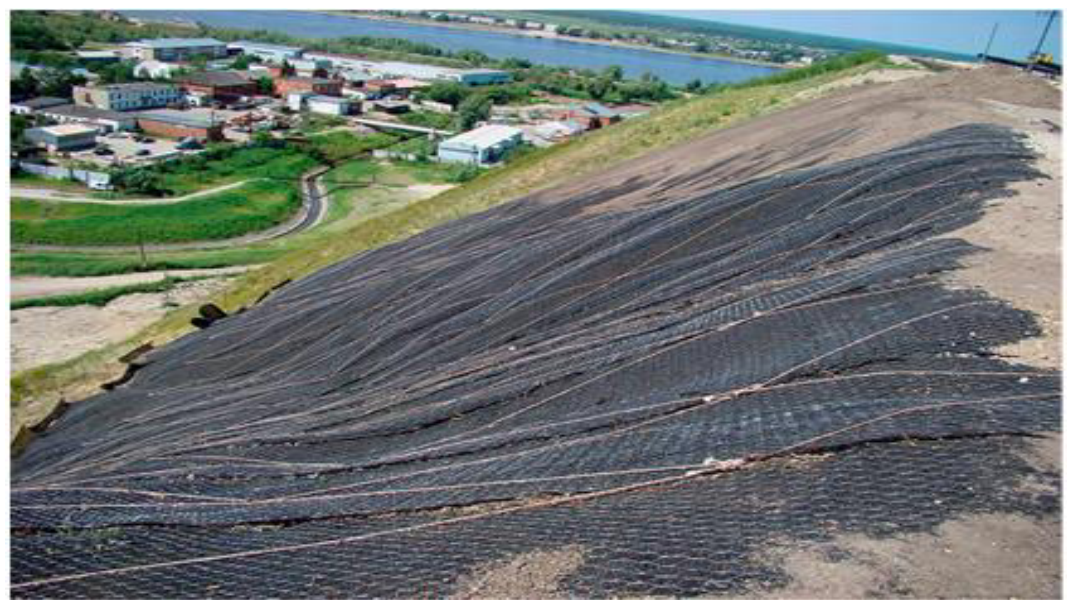

Fig. 5. Work to strengthen the slopes of Troitskiy Cape.

Restoration technique was aimed to preserve the authenticity of the monuments, where introduced elements in the process of restoration must be historically accurate. As well the conception of maximum preservation and reconstruction of most ancient of original architectural forms was approved [5]. 


\section{Conclusion}

Given the above, it can be concluded that the main objectives of the survey of cultural heritage objects during the production of the work is to identify the actual technical condition and constructional features of all-open constructions during work operational development of recommendations (or adjustment of the main recommendations of the survey) to restore the load bearing capacity of structures and ensure preservation of the object, prompt adjustment of design solutions together with representatives of the organization performing designing [17].

The offered functional model of formation of base of monitoring of buildingsmonuments allows to solve more operatively a problem of preservation of a disappearing heritage by acceptance of optimum timely decisions on elimination of arising refusals and other deviations from steady and their reliable functioning [19].

\section{References}

1. V.N. Azarov, A.A. Kuzmichev, Sociology of City 2, 76-86 (2015)

2. V. Kucera, S. Fitz, Water, air and soil pollution 1,153-154 (1995)

3. M. Peniüa, Procedia Engineering 117,883-890 (2015)

4. A.A. Kuzmichev, V.F. Loboyko, Procedia Engineering 150, 2095-2101 (2016)

5. V.A. Stolbova, L.I. Pavlova, Real Estate: Economics2,76-84 (2015)

6. E.Z. Kordatos, D.A. Exarchos, C. Stavrakos, A. Moropoulou, T.E. Matikas,Construction and Building Materials 48, 1261-1265(2013)

7. S.K. Kourkoulis, E.D. Pasiou, D. Triantis, I. Stavrakas, G. Hloupis, Procedia Engineering 109, 268-275(2015)

8. M.Kisternaya, V.Kozlov, Journal of Cultural Heritage 13, 74-78(2012)

9. G. Gülker, H. Helmers, K.D. Hinsch, P. Meinlschmidt, K. Wolff, Optics and Lasers in Engineering 24, 183-213(1996)

10. I.Kuznetsova, D. Kuznetsova, X.Rakova, Procedia Engineering 100, 1625-1633 (2015)

11. G.Sabatini, M.Giamello, R.Pini, S.Siano, R.Salimbeni, Journal of Cultural Heritage 1, 9-19 (2000)

12. T.P.Cooper, Technology and European Cultural Heritage, 465-468 (1991)

13. R.Vicente, T. M. Ferreira, J.A. Raimundo, M. da Silva, Journal of Cultural Heritage16, 1-14 (2015)

14. R. Douglas-Jones, J. J. Hughes, S. Jones, T. Yarrow, Journal of Cultural Heritage 21, 823-833(2016)

15. O.Risbol, C.Briese, M.Doneus, A.Nesbakken, Journal of Cultural Heritage 16, 202-209 (2015)

16. L.F. Ramos, L. Marques, P.B. Lourenço, G. De Roeck, A. Campos-Costa, J. Roque, Mechanical Systems and Signal Processing 24, 1291-1305 (2010)

17. P.C. Guzmán, A.R. Pereira Roders, B.J.F. Colenbrander, An overview of global monitoring tools 60, 192-201(2017)

18. A.Chianese, F.Piccialli, Computers \& Electrical Engineering. 55, 27-38(2016)

19. V.A. Stolbova, Components of investment potential of development of separate industries of the national economy, 108-115 (2014) 